\title{
Crystal and Physiochemical Properties of 2-Aminoethanaminium 2-(Ethoxycarbonyl)-4,6-Dinitrophenolate
}

\author{
Abdel-Al Gaber ${ }^{1}$, Ahmed Geies ${ }^{1}$, Mohamed Abdelazim²* \\ ${ }^{1}$ Faculty of Science, Chemistry Department, Assiut University, Assiut, Egypt \\ ${ }^{2}$ Chemical and Biotechnological Laboratories, College of Sugar Industry and Integrated Industries, Assiut University, Assiut, \\ Egypt \\ Email: *maboulela@icloud.com
}

How to cite this paper: Gaber, A., Geies, A. and Abdelazim, M. (2021) Crystal and Physiochemical Properties of 2-Aminoethanaminium 2-(Ethoxycarbonyl)-4,6-Dinitrophenolate. Open Access Library Journal, 8: e7764. https://doi.org/10.4236/oalib.1107764

Received: July 16, 2021

Accepted: August 2, 2021

Published: August 5, 2021

Copyright () 2021 by author(s) and Open Access Library Inc.

This work is licensed under the Creative Commons Attribution International License (CC BY 4.0).

http://creativecommons.org/licenses/by/4.0/ (c) (i) Open Access

\begin{abstract}
The proton transfer reaction of Ethyl 3,5-dinitrosalicylate, ethyl ester of 3,5-dinitrosalicylic acid (DNS), and ethylenediamine has been investigated. The reaction stoichiometry was $1: 1$ giving a molecular salt namely 2-Aminoethanaminium 2-(ethoxycarbonyl)-4,6-dinitrophenolate (AED). The single crystals were grown by the slow solvent evaporation technique using DMFwater as a solvent at room temperature and found in a dimeric form. The structure was confirmed by single crystal X-ray diffraction (XRD), Nuclear magnetic resonance (NMR), fourier-transform infrared (FT-IR), ultraviolet-visible (UV-Vis) spectroscopic techniques as well as thermal analysis (TGA/TDA). It is transparent between $460-1000 \mathrm{~nm}$ melts at $192^{\circ} \mathrm{C}$ and decomposes at $268^{\circ} \mathrm{C}$ and may found a suitable optical application. The title compound crystallizes in monoclinic crystal system with the centrosymmetric space group $\mathrm{C} 2 / \mathrm{c}$ and the title compound has shown superior properties in reducing sugar quantification as compared to DNS method.
\end{abstract}

\section{Subject Areas}

Analytical Chemistry

Keywords

AED, DNS, Crystal, Physiochemical, Spectral Properties, Thermal Properties

\section{Introduction}

Proton transfer interactions between electron donor and electron acceptor mo- 
lecules absorb radiation in the visible region leading to the formation of intensely colored charge transfer complexes [1] [2] [3] [4] [5].

Based on the concepts of the molecular and crystal engineering, the organic molecules exhibit many possibilities to tailoring the substances with desired properties through optimization of the microscopic hyper polarizabilities and the incorporation of the molecules in a crystalline lattice [6] [7] [8] [9].

3,5-dinitrosalicyclic acid is widely used in reducing sugar quantification [10] as well as its proton transfer investigation with many amines has been studied [11], no studies state the properties of these molecular salts in reducing sugar quantification.

In the present study, the proton transfer of ethyl ester of 3,5-dinitrosalicylic acid and ethylenediamine has been carried out and both of crystal and physicochemical product properties are outlined. It was expecting stoichiometry 2:1 acid to base but the X-ray crystallography confirmed the 1:1 molar ratio of the salt and it showed superior properties in reducing sugar quantification as compared to 3,5-dinitrosalicylic acid DNS [10].

\section{Experimental Procedure}

\subsection{Preparation of Ethyl 3,5-dinitrosalicylate}

Ethyl ester of DNS, 3,5-dinitro ethylsalicylate, was prepared according to both of the described proceures [12] and the described procedures [13] using ethyl salicylate instead of methyl salicylate, the products were identical in spectral analysis as well as physical propertie, pale yellow solid compounds, $\delta=1.3\left(\mathrm{t}, \mathrm{CH}_{3}\right.$ ester), 4.2 (q, $\mathrm{CH}_{2}$ ester), $8.4-8.6$ (m, $\mathrm{CH}$ aromatic), m.p. $73^{\circ} \mathrm{C}$, crystallized from ethanol-water $1: 1 \mathrm{v} / \mathrm{v}$. The purity was tested by thin layer chromatography (TLC).

\subsection{Preparation of 2 -Aminoethanaminium 2-(ethoxycarbonyl)-4,6-dinitrophenolate Salt}

Ethyl 3,5-dinitrosalicylate (1) (1 mmole) is dissolved in $10 \mathrm{ml}$ boiled absolute ethanol and ethylenediamine ( 4 mmole) is added, the mixture was boiled for five minutes. The yellow solid product formed (2) was filtered out, dried and recrystallized from water. Yellow solid, m.p $192^{\circ} \mathrm{C}$, Scheme 1.

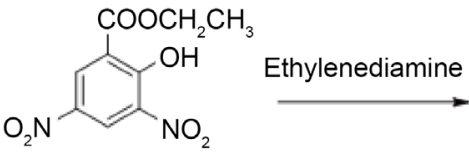

(1)

Ethyl 3,5-dinitrosalicylate

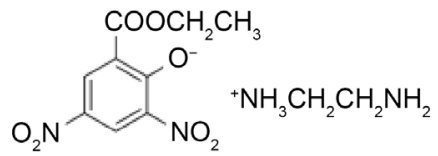

(2)

2-Aminoethanaminium 2-(ethoxycarbonyl)-4,6dinitrophenolate

\subsection{Single Crystal Growth}

A saturated DMF-water, dimethylformamide-water, solvent mixture of 2-Ami- 
noethanaminium 2-(ethoxycarbonyl)-4,6-dinitrophenolate salt (AED) was stirred for half an hour and filtered through quantitative whatmann 41 grade filter paper, the clear solution was kept undisturbed in a clean environment for one week.

\subsection{Examination in Reducing Sugar Quantification}

Following the same procedures have been described by Miller and a recently published work [10] [14] [15] [16] [17].

\section{Results and Discussion}

\subsection{Nuclear Magnetic Resonance Studies (NMR)}

The ${ }^{1} \mathrm{H}$ and ${ }^{13} \mathrm{C}$ NMR spectra of 2-Aminoethanaminium 2-(ethoxycarbonyl)-4,6dinitrophenolate (AED) were recorded using the BRUKER AC $400 \mathrm{MHz}$ spectrophotometer with TMS as the internal reference standard and DMSO as a solvent.

$\delta=1.3$ (t, $\mathrm{CH}_{3}$ ester), 4.2 (q, $\mathrm{CH}_{2}$ ester), 3.7 (s, $\mathrm{CH}_{2}$ adjacent $\mathrm{NH}_{3}^{+}$), 7.8 (s, $\left.{ }^{+} \mathrm{NH}_{3}\right), 8.4-8.6\left(\mathrm{~m}, \mathrm{CH}\right.$ aromatic), $2.7\left(\mathrm{~s}, \mathrm{CH}_{2}\right.$ adjacent $\left.\mathrm{NH}_{2}\right), 2.9\left(\mathrm{~s}, \mathrm{NH}_{2}\right),{ }^{13} \mathrm{C}$ $\mathrm{NMR}$ in DMSO, 14.15 ppm for $\mathrm{CH}_{3}$ ester carbon, $60.01 \mathrm{ppm}$ for $\mathrm{CH}_{2}$ ester carbon, $165.15 \mathrm{ppm}$ for $\mathrm{C}=\mathrm{O}$ ester, $36.66 \mathrm{ppm}$ for $\mathrm{CH}_{2}$ ethylenediamine carbon, 123.78 - $139.98 \mathrm{ppm}$ for aromatic carbons and $167.17 \mathrm{ppm}$ for aromatic carbon attached to ester group.

The title crystal shows eight proton signals indicating the presence of eight different proton environments in the aminium crystal. The broad hump appearing at $\delta 7.8 \mathrm{ppm}$ is assigned to the highly deshielded $\mathrm{NH}_{3}^{+}$protons. The intense singlet signal appearing at $\delta 8.4-8.6 \mathrm{ppm}$ has been assigned to aromatic protons. The intense signal at $3.7 \mathrm{ppm}$ is assigned to the methylene group beside the highly shielded aminium group and another signal appeared at $2.7 \mathrm{ppm}$ for methylene adjacent to the free amino group.

\subsection{Fourier-Transform Spectroscopy (FT-IR)}

The characteristic vibrational frequencies of the functional groups of the aminium salt are identified from the fourier transform infrared (FT-IR) spectrum recorded in the range of $4000-400 \mathrm{~cm}^{-1}$ employing Shimadzu Affinity $1 S$ FT-IR spectrometer. The formation of charge transfer complex during the acid-base interaction of ethylenediamine with ethyl 3,5-dinitrosalicylate is strongly evidenced through the realization of important bands in the complex salt. The absorption at $3194 \mathrm{~cm}^{-1}$ is due to the $+\mathrm{N}-\mathrm{H}$ stretching vibration. The absorption band at $3060 \mathrm{~cm}^{-1}$ corresponds to aromatic C-H asymmetric stretching vibration. The broad absorption bands in the region 3400 to $3600 \mathrm{~cm}^{-1}$ are due to $\mathrm{NH}_{2}$ asymmetric and symmetric stretching vibration. The absorptions at 1535 and $1359 \mathrm{~cm}^{-1}$ confirm the asymmetric and symmetric stretching vibrations of $\mathrm{NO}_{2}$ group respectively. The $\mathrm{C}=\mathrm{O}$ stretching vibration is observed at $1680 \mathrm{~cm}^{-1}$. 


\subsection{Single Crystal X-Ray Diffraction Studies (XRD)}

A yellow chip crystal having approximate dimensions of $0.500 \times 0.300 \times 0.300$ $\mathrm{mm}$ was mounted on a glass fiber. All measurements were made on a Rigaku SCX mini diffractometer using graphite monochromated Mo-K $\alpha$ radiation. The crystal-to-detector distance was $52.00 \mathrm{~mm}$.

The crystal structure analyses reveal it is crystallized in monoclinic crystal structure with centrosymmetric space group $\mathrm{C} 2 / \mathrm{c}$ and the unit cell parameters are $\mathrm{a}=15.289(2) \AA, \mathrm{b}=20.755(3) \AA$ and $\mathrm{c}=20.545$ (3) $\AA$. The crystal structure has been already deposited in Cambridge Crystallographic Data Center coded CCDC 1441586, Figure 1 represents the molecular ORTEP diagram for the aminium salt [14].

Some of the crystal data are listed (Table 1).

\subsection{Ultraviolet-Visible spectroscopy (UV-Vis)}

The optical transmission spectrum of the aminium salt was recorded in the region 400 - $1000 \mathrm{~nm}$ employing a Shimadzu $1061 \mathrm{UV}$-Vis spectrophotometer in

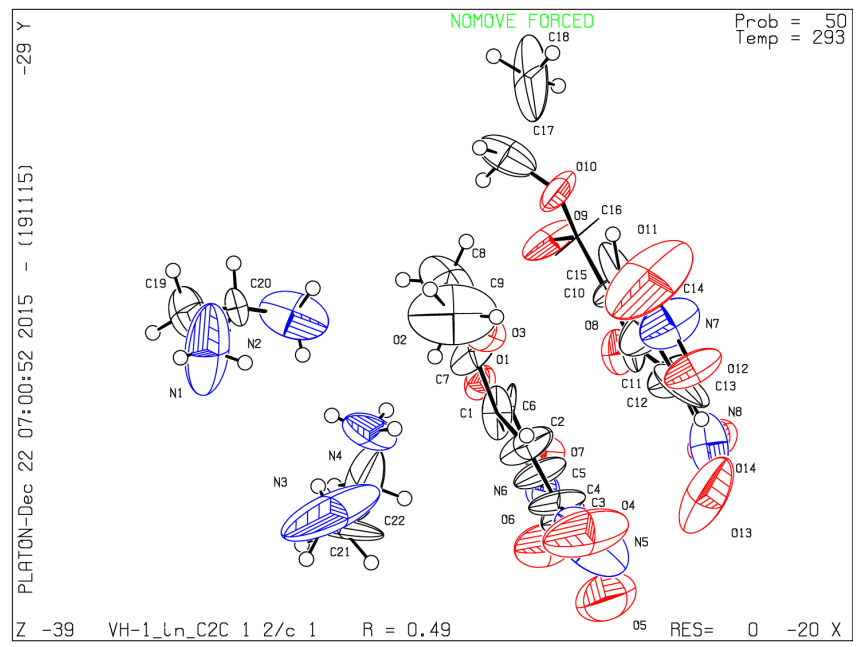

Figure 1. The molecular ORTEP diagram for 2-aminoethanaminium 2-(ethoxycarbonyl)-4,6-dinitrophenolate.

Table 1. Crytal data.

\begin{tabular}{cc}
\hline Empirical Formula & $\mathrm{C}_{22} \mathrm{H}_{33} \mathrm{~N}_{8} \mathrm{O}_{14}$ \\
\hline Formula Weight & 633.55 \\
Crystal Color, Habit & yellow, chip \\
& $\mathrm{a}=15.289(2) \AA$ \\
Lattice Parameters & $\mathrm{b}=20.755(3) \AA$ \\
& $\mathrm{c}=20.545(3) \AA$ \\
& $\beta=100.283(3)$ \\
Space Group & $\mathrm{V}=6415(2) \AA$ \\
$\mathrm{M}(\mathrm{MoK} \alpha)$ & $\mathrm{C} 2 / \mathrm{c}(\# 15)$ \\
& $1.103 \mathrm{~cm}^{-1}$
\end{tabular}


solution using DMSO as the solvent. The percentage of transmittance was around 100 in the region between 460 and $1000 \mathrm{~nm}$. Hence, this crystal can be used for the suitable optical applications due to its wide transparency range in the part of visible region above $460 \mathrm{~nm}$.

\subsection{Thermal analysis (TG/DTA)}

TG/DTA analysis, the sample is analyzed between $25^{\circ} \mathrm{C}-600^{\circ} \mathrm{C}$ at a heating rate $10 \mathrm{~K} / \mathrm{min}$ in nitrogen atmosphere. The DTA reveals exactly same changes shown by the TGA. From thermo gravimetric curve it is inferred that the material decomposes immediately after melting into gaseous products. The material exhibits sharp weight loss at $192.47^{\circ} \mathrm{C}$ and below this temperature no significant weight loss. The endothermic peak appears at $190.97^{\circ} \mathrm{C}$ in DTA corresponds to the melting point of the compound and another sharp exothermic peak at $268.84^{\circ} \mathrm{C}$ may be attributed to decomposition temperature of the aminium salt.

\section{Conclusion}

The organic molecular charge transfer salt 2-Aminoethanaminium 2-(ethoxycarbonyl)-4,6-dinitrophenolate (AED) was synthesized and the single crystals were grown by slow evaporation solution growth technique using DMF-water as the solvent. FT-IR, ${ }^{1} \mathrm{H}$ and ${ }^{13} \mathrm{C}$ NMR spectral techniques confirm the molecular structure of the aminium salt. The single crystal XRD study reveals that it crystallizes in monoclinic crystal structure with centrosymmetric space group $\mathrm{C} 2 / \mathrm{c}$ and the unit cell parameters are $\mathrm{a}=15.289(2) \AA, \mathrm{b}=20.755(3) \AA$ and $\mathrm{c}=$ 20.545(3) $\AA$. UV-Vis transmittance study shows that the attained percentage of transmission was around $100 \%$ for the aminium salt in the region between 460 $1000 \mathrm{~nm}$. The title crystal is a good candidate for suitable optical applications as well as its superior properties in reducing sugar quantification.

\section{Acknowledgements}

I express my deep sense of gratitude to the Indian Council for Cultural Relations for both funding me and giving me the opportunity to do a research in India and also my great appreciation to the Center of Excellence in Drug Discovery at NFDD Complex, Saurashtra University Campus, Rajkot, India, for all facilities I have been supported.

\section{Conflicts of Interest}

The authors declare no conflicts of interest.

\section{References}

[1] Milliken, R.S. (1950) Structures of Complexes Formed by Halogen Molecules with Aromatic and with Oxygenated Solvents. Journal of American Chemical Society, 72 , 600-608. https://doi.org/10.1021/ja01157a151

[2] Hamed, M.M.H., Abdel-Hanid, M.I. and Mahmoud, M.R. (1998) Molecular Com- 
plexes of Some N-Aryl-Dithiocarbamates with $\pi$-Electron Acceptors. Monatshefte für Chemie, 129, 121-127. https://doi.org/10.1007/PL00010148

[3] Chandramohan, A., Bharathikannan, R., Kandhavelu, V., Chandrasekaran, J. and Kandhaswamy, M.A. (2008) Synthesis, Crystal Growth, Structural, Thermal and Optical Properties of Napthalene Picrate an Organic NLO Material. Spectrochimica Acta Part A, 71, 755-759. https://doi.org/10.1016/j.saa.2008.01.036

[4] Chandramohan, A., Bharathikannan, R., Kandhasamy, M.A., Chandrasekaran, J. and Kandavelu, V. (2008) Synthesis, Crystal Growth, Spectral, Thermal and Optical Properties of Acenaphthene Picrate. Crystal Research Technology, 43, 93-98. https://doi.org/10.1002/crat.200710949

[5] Chandramohan, A., Bharathikannan, R., Chandrasekaran, J., Maadeswaran, P., Renganathan, R. and Kandavelu, V. (2008) Synthesis, Crystal Growth and Characterization of a New Organic NLO Material: Caffeinium Picrate (CAFP) - A Charge Transfer Molecular Complex Salt. Journal of Crystal Growth, 310, 5409-5415. https://doi.org/10.1016/j.jcrysgro.2008.09.020

[6] Josse, D., Hierle, R., Ledoux, I. and Zyss, J. (1988) Highly Effiecient Second Harmonic Generation of Picoseconds Pulses at $1.32 \mu \mathrm{m}$ in 3-Methyl-4-nitropyridine1-oxide. Applied physics Letters, 53, 2251-2253.

https://doi.org/10.1063/1.100413

[7] Levine, B.F., Bethea, C.G., Thurmond, C.D., Lynch, R.T. and Bernstein, J.L. (1979) An Organic Crystal with an Exceptionally Large Optical Second Harmonic Coefficient: 2-Methyl-4-nitroaniline. Journal of Applied Physics, 50, 2523-2527. https://doi.org/10.1063/1.326248

[8] Gunter, P. (2009) Nonlinear Optics Laboratory. ETH-Hong-gerberg, Zurich.

[9] Hierle, R., Badan, J. and Zyss, J. (1984) Growth and Characterization of a New Material for Nonlinear Optics: Methyl-3-nitro-4-pyridine-1-oxide (POM). Journal of Crystal Growth, 69, 545-554. https://doi.org/10.1016/0022-0248(84)90366-X

[10] Miller, G.L. (1959) The Use of 3,5-Dinitrosalicylic Acid in Reducing Sugar Quantification. Analytical Chemistry, 31, 462-428. https://doi.org/10.1021/ac60147a030

[11] Smith, G., Wermuth, U.D., Healy, P.C. and White, J.M. (2003) Structure-Making with 3,5-Dinitrosalicylic Acid. II. The Proton-Transfer Compounds of 3,5-Dinitrosalicylic Acid with the Monocyclic Heteroaromatic Amines. Australian Journal of Chemistry, 56, 707-713. https://doi.org/10.1071/CH02163

[12] William, M. (1942) Ethyl Dinitro Salicylate as an Insecticide. US Patent No. 2281857A.

[13] Douglas, T.L., Clonce, A.J. and Jones, G.C. (1984) Process Inhibitor for Readily Polymerizable Ethylenically Unsaturated Aromatic Compounds. US Patent No. 4439278 A.

[14] Zohri, A.-N., Abdelazim, M. and Ibrahim, S. (2018) 2-Aminoethanaminium 2-(ethoxycarbonyl)-4,6-dinitrophenolate as a Greener Route in Reducing Sugar Quantification. MethodsX, 5, 609-612. https://doi.org/10.1016/j.mex.2018.05.017

[15] Shah, V.H., Zohri, A.-N., Talpara, P.K., Dubal, G. and Abdelazim, M. (2016) Crystal Structure Determination, CCDC 1441586.

[16] Zohri, A.-N., Abdelwahab, M., Ali, M., Ibrahim, S. and Abdelazim, M. (2019) Data on Morphological Features Change of Pre-Hydrolysis Treated Sugarcane Bagasse Using in Situ Sodium Hydroxide-Sodium Bisulfate Method. Data in Brief, 24, Article ID: 103971. https://doi.org/10.1016/j.dib.2019.103971

[17] Geies, A., Abdelazim, M., Sayed, A.M. and Ibrahim, S. (2020) Thermal, Morpho- 
logical and Cytotoxicity Characterization of Hardwood Lignins Isolated by in-Situ Sodium Hydroxide-Sodium Bisulfate Method. Natural Resources, 11, 427-438. https://doi.org/10.4236/nr.2020.1110025 